Historia y comunicación social

ISSN-e 1988-3056

https://dx.doi.org/10.5209/hics.66313

Ibáñez Fanés, Jordi (ed.): En la era de la posverdad. 14 ensayos. Editado por Calambur (colección criterios), Barcelona, 2017, 197 páginas. ISBN. 978-84-8359417-9

\title{
Ideas iniciales
}

Jordi Ibáñez coordina una obra coral en la que participan autores pertenecientes a disciplinas como el periodismo, la ciencia política o la filosofía, aspecto que corrobora las numerosas aristas y la complejidad del objeto de estudio abordado: la posverdad. En efecto, nos hallamos ante la palabra del año para el diccionario Oxford en 2016. No obstante, este mediático vocablo goza de profundas raíces históricas, si bien determinados acontecimientos recientes lo han expoleado, destacando el referendo que dio como resultado el Brexit o las últimas elecciones presidenciales celebradas en Estados Unidos las cuales arrojaron la victoria de Donald Trump.

No obstante, como advierte Valentí Puig, ni Donald Trump, ni los Brexiters han inventado la posverdad. Por el contrario, han visto en aquélla una ventana de oportunidad para la transmisión de su mensaje, asumiendo para ello unas reglas del juego ya trazadas de antemano, en particular la que aludía al carácter relativo de la verdad, al ser considera ésta una mera construcción social. De hecho, cuando el Doctor Miquel Pellicer aborda en su obra La comunicación en la era Trump (UOC, 2017), la relación Trump-medios de comunicación lleva a cabo afirmaciones políticamente incorrectas pero repletas de sensatez, en tanto en cuanto pone de manifiesto un cierto adanismo perceptible en el periodismo que se practica a ambos lados del Atlántico: "me fascina la ligereza con la que muchos medios de comunicación y analistas han tratado al candidato Trump y lo siguen haciendo como presidente. El magnate puede ser muchas cosas, pero no es un advenedizo ni un estúpido. Te puede gustar o no su ideología pero jamás puedes infravalorar sus capacidades” (p.22).

\section{Lo propio de la posverdad}

La posverdad comparte rasgos con otros fenómenos que se han desarrollado a lo largo de la historia, en especial con la propaganda. Sin embargo, como puntualiza Jordi Ibáñez, propaganda y posverdad no pueden considerarse sinónimos, existiendo diferencias de calado entre ambas. En efecto, en la posverdad se dan cita dos actores cuyos roles se hallan delimitados con nitidez: por un lado, el ciudadano que sólo escucha lo que le gusta oír; por otro lado, el político que no se preocupa en contrastar lo que afirma, sino en agradar con sus intervenciones a sus seguidores. Por tanto, ante los hechos tangibles la posverdad mostrará absoluta indiferencia, incluso des- 
precio como refrenda el recurso a expresiones del tipo "hechos alternativos", pues de lo que se trata es de apelar a las emociones.

En íntima relación con esta última idea, Nora Catelli sentencia que uno de los rasgos definitorios de la posverdad es que no se puede refutar, adquiriendo una suerte de validez universal. En palabras de la citada autora: “ ¿por qué escandalizarse entonces de que las afirmaciones que circulan por la red no se sometan a ningún tipo de comprobación o, que si esto sucede, la comprobación no modifique la afirmación previa ni la neutralice?” (p.141). Asimismo, sobre esta cuestión, Marta Sanz aporta un dato fundamental: herramientas legislativas como la denominada "Ley Mordaza" no van a suponer un freno para la posverdad, es decir, para la difusión deliberada de mentiras, emitidas siempre con una intencionalidad política y/o económica, lo que en última instancia socava la calidad de la democracia y pone en tela de juicio la capacidad de determinados actores, por ejemplo los medios de comunicación, para fiscalizar al poder.

La posverdad ha sabido manejar con precisión y eficacia las enormes posibilidades que las nuevas tecnologías de la comunicación ofrecen hoy en día. Al respecto, Manuel Arias Maldonado hace una revisión crítica de aquéllas, señalando que no han mejorado el nivel de la conversación puesto que en la red social sólo se concede validez a las voces con cuyos puntos de vista nos identificamos, lo que automáticamente genera el narcisismo del sujeto emisor. En relación con este argumento, para Victoria Camps "en la era de la información, ni ésta ni el conocimiento brillan especialmente, basta la comunicación vacía” (p. 99). De hecho, como indica Marta Sanz, existe una mala calidad de la libertad de expresión y unas fallas en el sistema educativo, origen en última instancia de las violencias sistémicas.

\section{Depurando responsabilidades, enumerando culpables}

Con todo lo expuesto, la pregunta pertinente podría ser ¿cómo hemos llegado a este escenario en el cual todo es verdad? Para responder a este interrogante, los autores de la obra coordinada por Jordi Ibáñez realizan una serie de observaciones que ponen el acento en la labor desempeñada desde hace unas décadas por los intelectuales. Así, alejándose de cualquier corporativismo, efectúan una crítica, demoledora en ocasiones, al trabajo de aquéllos, en particular a su elitismo pues éste encierra una exención de culpas: "en el origen de la posverdad asoma la hipertrofia y mecanización de abusos, silencios u omisiones de intelectuales y periodistas serios ante conflictos político-ideológicos. Esa semilla ha desarrollado su deformidad bajo control de otros poderes y otras intenciones: se fabrican de forma planificada para convertirse en pandemia corrupta y corruptora”, sentencia Jordi Gracia (págs. 40-41).

En efecto, los intelectuales de generaciones pasadas hicieron mucho por descalificar el concepto de verdad, apostando decididamente por la existencia de "varias verdades", un escenario que autores como Ken Wilberg en su obra Trump y la posverdad (Kairos, 2018) han condenado de manera rotunda y al que también se refiere Manuel Arias Maldonado: "la posverdad nos indica que la propia noción de verdad, y más concretamente de verdad pública, habría dejado de tener sentido. De hecho, estaría siendo reemplazada por la idea de que coexisten distintas "verdades" en el cuerpo social, sin que nada parecido a una verdad única pueda establecerse o reconocerse" (p. 67). 
Victoria Camps complementa la anterior aseveración: "el razonamiento era este: dado que la verdad no es monopolio de nadie, que es prácticamente inalcanzable, dado que los puntos de vista son diversos y plurales, puesto que estamos en la posmodernidad, en la era del pensamiento débil y la sociedad líquida, ¿a qué viene preocuparse por buscar la verdad?" (p. 95). Dicho con otras palabras, se produjo un rechazo de la autoridad y de la razón, lo que obviamente repercutió negativamente en el concepto de verdad, identificada como señala Domingo Ródenas con el dogmatismo, lo que justificaba su rechazo.

\section{En conclusión}

Una obra valiente en la que los autores abordan, sin caer en el dogmatismo, un fenómeno complejo como es la posverdad, diseccionando sus partes constituyentes, analizando las razones de su apogeo actual y explicitando los peligros que encierra su presencia protagonista en la vida pública.

Alfredo Crespo Alcázar Universidad Antonio de Nebrija (Madrid) y Universidad Internacional de Valencia (VIU) alfredocrespoalcazar1974@gmail.com 